\title{
Complete "stress-strain" diagrams of rolled steal beams
}

\author{
Stanislav Fomin ${ }^{1, *}$, Yuriy Izbash $^{1}$, Yuriy Bondarenko ${ }^{1}$, Serhii Butenko ${ }^{1}$, and Iryna \\ Plakhotnikova ${ }^{1}$ \\ ${ }^{1}$ Kharkiv National University of Construction and Architecture, 61002, Kharkiv, vul. Sumska, build. \\ 40, Ukraine
}

\begin{abstract}
This paper covers features of rolled steel beams used in composite structures. Composite structures consist of reinforced concrete slabs and rolled steel beams. To calculate its fire resistance it is necessary to know their complete "stress-strain" diagrams. Steel girders, which work together with reinforced concrete slabs, are widely used in bridge building. The tests on samples cut from web and a rack of an I-beam were conducted. The results of experimental studies of the "stress-strain" diagrams of rolled beams indicate the difference in the physicalmechanical characteristics of steel in the web and flanges of the beams. The experimental studies of diagrams were carried out at temperatures of $20,400,500,600,700$ and $800^{\circ} \mathrm{C}$. The properties of the steel were significantly affected by the temperature. The "stress-strain" diagrams of rolled beams and table of results of experimental studies were obtained. The complete "stress-strain" diagrams of the rolled beams were studied. Experimental studies have been conducted using a newly developed patented installation. The differences of diagrams in the web and flanges of the steel I-beams were found.
\end{abstract}

\section{General provision}

Composite structures consist of reinforced concrete slabs and rolled steel beams. To calculate its fire resistance it is necessary to know their complete "stress-strain" diagrams. Steel girders, which work together with reinforced concrete slabs, are widely used in bridge building.

The design of steel structures shall be carried out using the national standard, which corresponds to EN 1993-1-2:2005 Eurocode 3: Design of steel structures - Part 1-2: General rules - Structure fire design - Part 1-2: General rules - Calculation for fire resistance [1].

The mechanical properties of structural steels are determined by the National Institute of Standards and Technology (NIST). (2005) [2]. The behavior of high-strength structural steel at elevated temperatures is described in [3]. The behavior of steel framework in a fire condition, described in a candidate's dissertation [4] (University of Edinburgh, 2000); nonlinear analysis for a three-dimensional steel framework in a fire conditions is carried out

\footnotetext{
* Corresponding author: sfomin@ukr.net
} 
in [5], mechanical properties of structural steel at elevated temperatures and after cooling are described in [6]. In [7] experimental studies of the critical temperature of compressed steel elements with limited thermal elongation are presented, and the fire resistance of steel columns with axial extensions and bending is investigated in [8]. The manufacture of I-beams by the hot rolling method is described in [9].

This paper considers features of rolled steel beam and tests on samples.

\section{Technology for the production of steel twisted beam using the hot rolling method}

Hot rolling of I-beams shall be carried out on rolling mills, which are long installations with a large number of rotating rolls of different diameters. The process involves the use of thick ingots or slabs that have a continuous section as a workpiece. When rolling, the ingots are moved along the roller table and processed using rollers, as a result of which the length of the workpieces is greatly increased, and the cross-section gradually decreases and becomes "I" shaped.
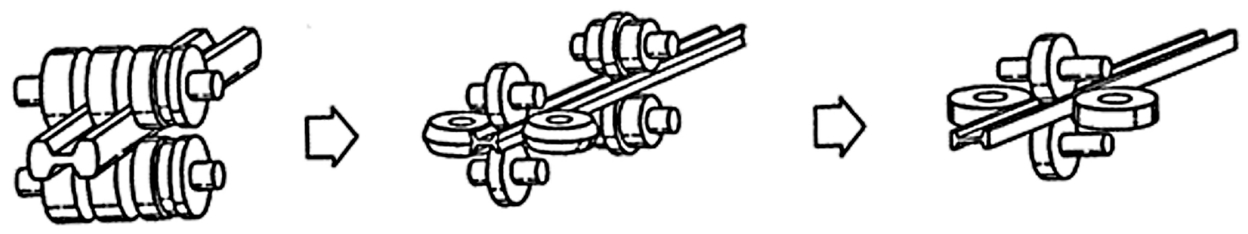

Fig. 1. The beam processing using rollers.

The method of hot rolling of I-beam is extremely effective. I-beam has unique mechanical properties. Its strength exceeds the strength of L-bar and square profile, and it has a high rigidity and a small specific density. In addition, one of the main structural properties of an I-beam is bending resistance, that is, to take over and transmit the vertical and horizontal load.

Beams have two types of flanges: with the sloping of internal faces of flanges; with parallel faces of flanges.

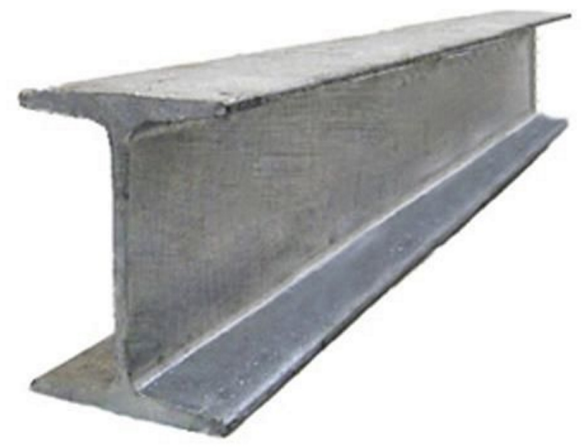

Fig. 2. The I-beam with sloping of faces of flanges.

Three types of I-beams are manufactured based on the ratio of sizes and purpose: (A) normal (B); column (K) wide-flanged (W); steel beams are the most demanded type of high-quality section-shaped rolled stock, thanks to a number of advantages: simplicity of design; ability to withheld increased loads; they allow large spans; they not burn (although 
they loss their bearing capacity when heated to the high temperature); they are resistant to the biological effects.

It can be assumed that different parts of beams have different stresses of compression at such rolling and their properties can differ from each other, all the more at influence of the high temperature. To check this assumption, the experimental studies were conducted using the new installation (testing stand), which was developed and patented by us [10].

\section{Testing of samples}

The stand for testing reinforcement that includes a metal frame, device for gripping the armature, devices for creation and measurement of the dynamic load, and measurement of deformations, system for the reinforcement heating, which is characterized in that the devices for gripping the reinforcement are connected with the system for creation of the dosed movements made of the worm movement gears with the steering wheels mounted on the pivot supports.

The operation principle of the reinforcement testing stand is as follows. The reinforcement sample is fixed in the collect clamps, heated to a given temperature by electric power and stretched for given displacements without accumulation of potential energy in the elements of the installation using the worm gears with steering wheels that create the system of the dosed movement. The value of the reinforcement deformation shall be measured using an extensometer with traction rods and indicators, the force value is indicated by the dynamometer. This allows us to obtain a complete "stress-strain" diagram of the reinforcement with a descending branch at elevated and high temperatures.

The tests were carried out on samples taken from the web and vertical member of the I-beam series 2062 with height $H=200 \mathrm{~mm}$, width of the upper and lower flanges $100 \mathrm{~mm}$, thickness $T_{f}=8.6 \mathrm{~mm}$, the thickness of web $-T_{b}=5.2 \mathrm{~mm}$, cross section area $27.7 \mathrm{~mm}$, used during experimental research of fragments of composite structures of bridges during heating.

Samples are shown in Fig. 3.

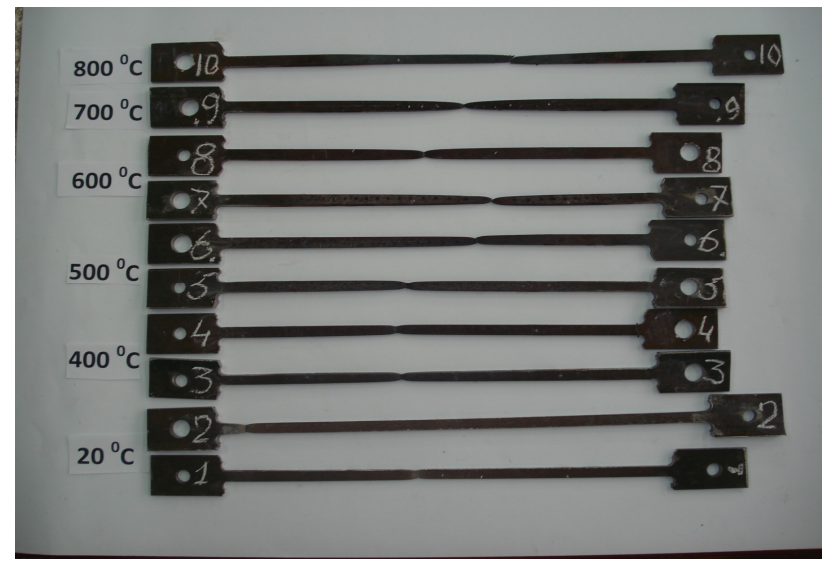

Fig. 3. The samples that were cut from the web and vertical member of the I-beam. 


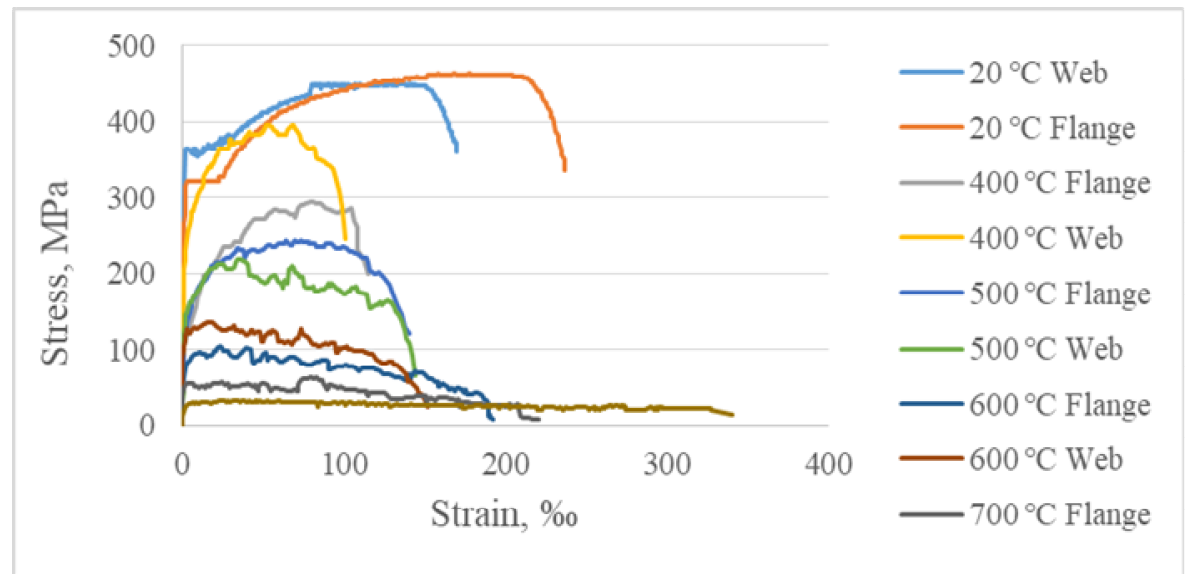

Fig. 4. General "stress-strain" diagrams (for web and flanges).

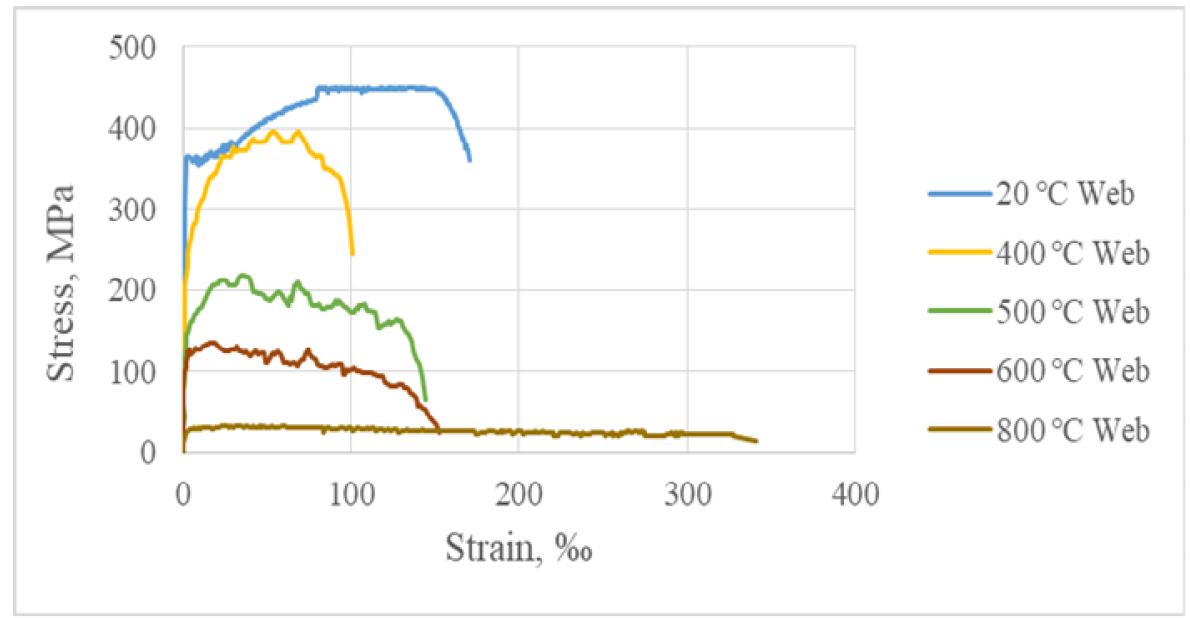

Fig. 5. "Stress-strain" diagrams for web of rolled beams.

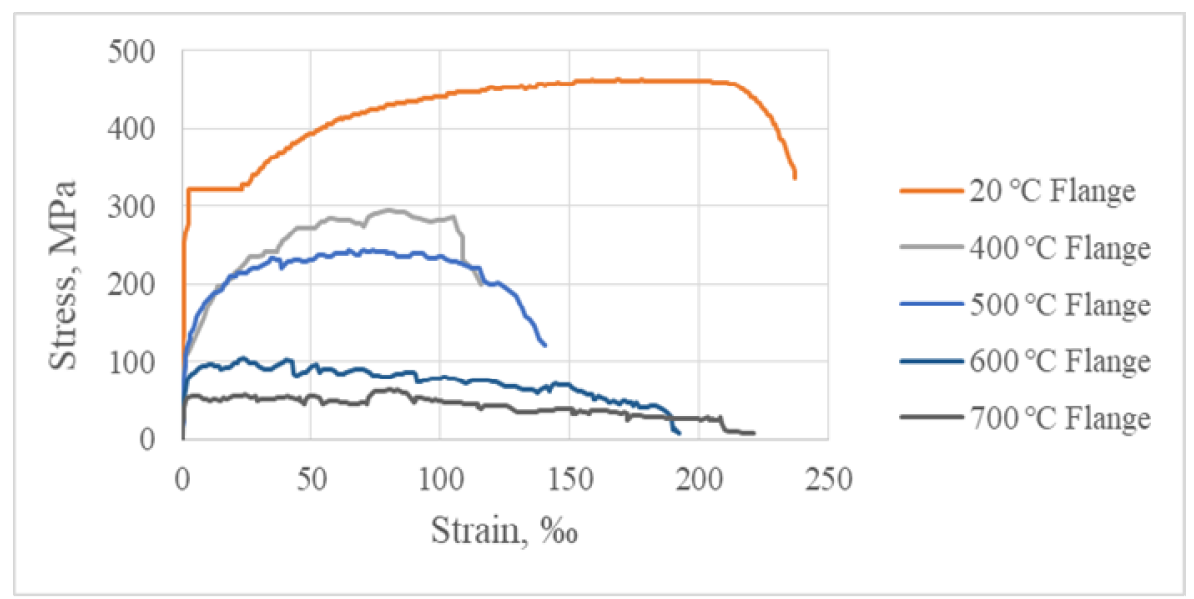

Fig. 6. "Stress-strain" diagrams for flanges of rolled beams. 
Table 1. Results of study of "stress-strain" diagrams of rolled beams.

\begin{tabular}{|c|c|c|l|l|l|l|l|l|}
\hline $\begin{array}{c}\text { No. } \\
\text { of a } \\
\text { diagram }\end{array}$ & $\begin{array}{c}\text { Tempe- } \\
\text { rature } \\
{ }^{\circ} \mathrm{C}\end{array}$ & $\begin{array}{c}\text { Part } \\
\text { of } \\
\text { beam }\end{array}$ & $\begin{array}{c}\text { Deforma- } \\
\text { tion, } \\
\% \text { on }\end{array}$ & Stress, MPa & $\begin{array}{c}\text { Straight } \\
\text { line }\end{array}$ & $\begin{array}{c}\text { Yield } \\
\text { point }\end{array}$ & $\begin{array}{c}\text { Maxi- } \\
\text { mum } \\
\text { stress }\end{array}$ & Destruction \\
\hline 1 & 20 & wall & $\%$ o & & 2.2 & 15 & 79.5 & 170.3 \\
\hline 2 & 20 & flange & $\% 0$ & & 2.9 & 22.9 & 197.1 & 237 \\
\hline & & & & $\mathrm{MPa}$ & 320 & 320.8 & 469.5 & 396.5 \\
\hline 3 & 400 & wall & $\% 0$ & & 1.4 & - & 56.6 & 99.4 \\
\hline & & & & $\mathrm{MPa}$ & 190 & & 395 & 287 \\
\hline 4 & 400 & flange & $\% 0$ & & 1.7 & - & 79.1 & 115.6 \\
\hline & & & & $\mathrm{MPa}$ & 106 & & 294 & 208 \\
\hline 5 & 500 & wall & $\% 0$ & & 1.9 & - & 35.5 & 144.7 \\
\hline & & & & $\mathrm{MPa}$ & 133 & & 219 & 65.5 \\
\hline 6 & 500 & flange & $\% 0$ & & 1.425 & - & 72.7 & 140 \\
\hline & & & & $\mathrm{MPa}$ & 119.6 & & 243 & 122 \\
\hline 7 & 600 & wall & $\% 0$ & & 0.475 & - & 18.3 & 152.5 \\
\hline & & & & $\mathrm{MPa}$ & 80.7 & & 135.8 & 24.5 \\
\hline 8 & 600 & flange & $\% 0$ & & 3.05 & - & 23.82 & 191 \\
\hline & & & & $\mathrm{MPa}$ & 82 & & 105 & 12 \\
\hline 9 & 700 & flange & $\% 0$ & & 0.7 & - & 79.5 & 217 \\
\hline & & & & $\mathrm{MPa}$ & 40.4 & & 63.3 & 8.9 \\
\hline 10 & 800 & wall & $\% 0$ & & 4.4 & - & 35.2 & 340 \\
\hline & & & & $\mathrm{MPa}$ & 28.6 & & 33.6 & 13.7 \\
\hline
\end{tabular}

\section{Results of experimental studies}

The results of experimental studies of the "stress-strain" diagrams of the rolled beams shown in Fig. 4 - 6 show the difference in physical and mechanical characteristics of steel in the web and flanges of beams.

So, at $20^{\circ} \mathrm{C}$ (Table 1), the transition of the direct line to the yield point in the wall occurred at stress of $363.7 \mathrm{MPa}$, and in the flange - at stress of $320.7 \mathrm{MPa}$. The maximum stress at the yield point in the wall occurred at $441.4 \mathrm{MPa}$, and in the flange - at stress of 469.5 $\mathrm{MPa}$, the destruction in the wall occurred at $359.8 \mathrm{MPa}$, in the flange - at stress of 396.5 MPa.

The properties of the steel were significantly affected by the temperature. Starting from $400{ }^{\circ} \mathrm{C}$, the yield point has disappeared. The maximum stress in the wall has occurred at stress of $395 \mathrm{MPa}$ and deformation $56.6 \%$, and in the flange - at stress of $294 \mathrm{MPa}$ and a deformation of $79.1 \%$; the destruction has occurred at stress of $287 \mathrm{MPa}$ and deformation of $99.4 \%$, and in the flange - at stress of $208 \mathrm{MPa}$ and deformation of $115.5 \%$.

At $500{ }^{\circ} \mathrm{C}$ the maximum stress in the wall has occurred at the stress of $133 \mathrm{MPa}$ and deformation of $1.9 \%$, in the flange - at stress of $119.6 \mathrm{MPa}$ and deformation of $1.42 \%$; destruction in the wall - at stress of $219 \mathrm{MPa}$ and deformation of $35.5 \%$, in the flange - at the stress of $243 \mathrm{MPa}$ and deformation of $72.7 \%$.

At $600{ }^{\circ} \mathrm{C}$ the maximum stress in the wall has occurred at the stress of $135.8 \mathrm{MPa}$ and deformation of $18.3 \%$, in the flange - at stress of $105 \mathrm{MPa}$ and deformation of $23.82 \%$; destruction in the wall - at stress of $24.5 \mathrm{MPa}$ and deformation of $152.5 \%$, in the flange at the stress of $12 \mathrm{MPa}$ and deformation of $191 \%$.

At $700{ }^{\circ} \mathrm{C}$, the maximum stress in the flange has occurred at the stress of $63.3 \mathrm{MPa}$ and deformation of $79.5 \%$, the destruction in the flange has occurred at the stress of $8.9 \mathrm{MPa}$ and deformation of $217 \%$. 
At $800^{\circ} \mathrm{C}$, the maximum stress in the flange has occurred at the stress of $33.6 \mathrm{MPa}$ and deformation of $32.2 \%$, the destruction in the flange has occurred at the stress of $137.9 \mathrm{MPa}$ and deformation of $340 \%$.

\section{Conclusions}

1. The complete "stress-strain" diagrams of the rolled beams were studied. Experimental studies have been conducted using a newly developed patented installation. The tests were carried out on samples taken from the web and vertical member of the I-beam series 2062 with height $H=200 \mathrm{~mm}$, width of the upper and lower flanges - $100 \mathrm{~mm}$, thickness $T_{f}=8.6 \mathrm{~mm}$, the thickness of web $-T_{b}=5.2 \mathrm{~mm}$, cross section area $-27.7 \mathrm{~mm}$, used during experimental research of fragments of composite structures of bridges during heating.

2. The "stress-strain" diagrams of rolled beams and table of results of experimental studies were obtained. The differences of diagrams in the web and flanges of the steel I-beams were found.

\section{References}

1. EN 1993-1-2:2005 Eurocode 3: Design of steel structures - Part 1-2: General rules Structure fire design (Eurocode 3: Design of steel structures - Part 1-2: General rules - Calculation for fire resistance) with a technical amendment EN 1993-1-2: 2005/AC:2009

2. National Institute of Standards and Technology (NIST). Mechanical Properties of Structural Steels. (2005)

3. J. Chen, B. Young, and B. Uy, J. of Struc. Eng., 132, 1948-1954, (2006)

4. M. Gillie, The behavior of steel-framed composite structures in fire conditions, $\mathrm{PhD}$ thesis, The University of Edinburgh, (2000)

5. S. Najjar, I. Burgess, Eng. Struc., 18, 77-89, (1996)

6. J. Outinen, P. Makelainen, F. and Mat., 28, 237-251, (2004)

7. J. Rodrigues, I. Neves, J. Valente, F. S. J., 35, 77-98, (2000)

8. J. Valente, I. Neves, J. of Constr. S. R., 52, 319-331, (1999)

9. A. P. Grudev, L. F. Mashkin, M. I. Khanin, Technology of Rolling Production (Metallurgy, 1994)

10. Patent for the utility model No. 120438. Testing stand for reinforcement. / Inventors: A. M. Kravchenko (UA), S. L. Fomin (UA), Y. M. Izbash (UA), S. V. Butenko (UA). Owner: State Enterprise "State Institute for design of the coke industry enterprises", SE "GIPROKOKS", vul. Sumska, building 60, m. Kharkiv, 61002 (UA), Bul. No. 20, $10 / 25 / 2017$ 